\title{
Altered patterns of differentiation in karyotypically abnormal human embryonic stem cells
}

\author{
ALIREZA FAZELI*,1, CHEE-GEE LIEW2,3, MARYAM M. MATIN" ${ }^{4}$ SARAH ELLIOTT ${ }^{1}$, LAURENT F.C. JEANMEURE5, \\ PHILLIP C. WRIGHT 6 , HARRY MOORE ${ }^{1,2}$ and PETER W. ANDREWS ${ }^{2}$ \\ ${ }^{1}$ The University of Sheffield, Academic Unit of Reproductive and Developmental Medicine, Sheffield, UK, ${ }^{2}$ Centre for Stem \\ Cell Biology and Department of Biomedical Science, University of Sheffield, Sheffield, UK, ${ }^{3}$ UCR Stem Cell Center, \\ University of California, CA, USA, ${ }^{4}$ Department of Biology and Institute of Biotechnology, Ferdowsi University of \\ Mashhad, Mashhad, Iran, ${ }^{5}$ Polymer Composites Research Group, Department of Mechanical, Materials and Manufacturing \\ Engineering, University of Nottingham, Nottingham, UK and ${ }^{6}$ Biological and Environmental Systems Group, Department \\ of Chemical and Process Engineering, The University of Sheffield, Sheffield, UK
}

\begin{abstract}
Upon prolonged culture, human embryonic stem (hES) cells undergo adaptation, exhibiting decreased population doubling times and increased cloning efficiencies, often associated with karyotypic changes. To test whether culture adaptation influences the patterns of differentiation of hES cells, we compared the expression of genes indicative of distinct embryonic lineages in the embryoid bodies produced from two early passage, karyotypically normal hES cell lines, and two late passage, karyotypically abnormal hES cell lines. One of the abnormal lines was a subline of one of the normal early passage lines. The embryoid bodies from each of the lines showed evidence of extensive differentiation. However, there were differences in the expression of several genes, indicating that the culture adapted hES cells show altered patterns of differentiation compared to karyotypically normal hES cells. The loss of induction of alphafetoprotein in the culture-adapted cells was especially marked, suggesting that they had a reduced capacity to produce extra-embryonic endoderm. These changes may contribute to the growth advantages of genetically variant cells, not only by reflecting an increased tendency to self renewal rather than to differentiate, but also by reducing spontaneous differentiation to derivatives that themselves may produce factors that could induce further differentiation of undifferentiated stem cells.
\end{abstract}

KEY WORDS: human embryonic stem cell, differentiation

\section{Introduction}

When human embryonic stem (hES) cell lines were first derived, they were seen to possess normal diploid karyotypes (Thomson et al. 1998). However, interest in the potential of hES cells for regenerative medicine is tempered by the recognition that these cells may acquire karyotypic changes during prolonged culture in vitro (Draper et al. 2004; Maitra et al. 2005). A striking feature of the reported karyotypic changes is that they commonly involve acquisition of extra copies of the same chromosomes, chromosomes 17 and 12 (Baker et al. 2007). Moreover, extra copies of these chromosomes, or more precisely the long arm of chromosome 17 (17q) and the short arm of chromosome 12 (12p), are also often found in human embryonal carcinoma (hEC) cells (Atkin \& Baker 1982; Skotheim et al. 2002), the pluripotent stem cells of teratocarcinomas and the malignant counterparts of hES cells. This commonality of genetic changes in hES cells in culture and hEC cells in tumors suggests a common cause. An obvious possibility is the selection for variants that affect the molecular

\footnotetext{
Abbreviations used in this paper: AFP, alphafetoprotein; bFGF, basic fibroblast growth factor; BMP-2, bone morphogenetic protein-2; CDH5, cadherin 5; VASA, DEAD/H BOX 4; DAZL, deleted in azoospermia-like; EB, embryoid body; EC, embryonal carcinoma; FC, fold change; GCK, glucokinase; GDF9, growth/differentiation Factor 9; hES, human embryonic stem; hEC, human embryonal carcinoma; INS, insulin; IPF1, insulin promoter factor 1; IGF, insulin-like growth factor; ISL1, ISL1 transcription factor; MAP2, microtubule-associated protein 2; MYOD1, myogenic differentiation antigen 1; Neuro D1, neurogenic differentiation 1; OCT4, octamer-binding transcription factor 4; PCA, principal component analysis; SLC2A2, solute carrier family 2; SD, standard deviation; SCP3, synaptonemal complex protein3; TLR4, toll-like receptor 4 .
} 
decision processes by which a pluripotent stem cell chooses between the alternative fates of apoptosis, differentiation or selfrenewal, leading to the observed shorter population doubling times and increased cloning efficiencies (Herszfeld et al. 2006). Such variant hES cells may eventually acquire malignant properties like embryonal carcinoma (EC) cells (Andrews et al. 2005; Herszfeld et al. 2006).

In teratocarcinomas, the malignant EC cells may lose the capacity for differentiation and progress towards a nullipotent state (Andrews 2002). Since loss of a capacity to differentiate is one way in which variant cells may acquire a growth advantage, we have now compared the differentiation potential of two early and two late passage, culture adapted human ES cell lines. Our results indicate that the culture adapted hES cells do show altered patterns of differentiation, compared to karyotypically normal hES cells.

\section{Results}

To assess the capacity of the different ES cell lines to differentiate, we compared the time course of differentiation in embryoid bodies (EBs) produced from an early passage, diploid subline, and a late passage, culture adapted subline of $\mathrm{H} 7$ (sublines $\mathrm{s} 14$ and s6, respectively) (2)(Enver et al. 2005), and also from two unrelated lines, Shef3, which was in early passage and diploid, and $\mathrm{H} 14$, which was in late passage and was trisomic for chromosome 17. Cell lineages derived from EBs were indicative of unbiased differentiation propensity for each hES cell line without culture manipulation. To allow statistically significant comparisons, five replicate EB cultures were set up from each line and samples of the EBs were then harvested from each culture after $3,5,7,14$ and 21 days. We observed efficient and similar EB formation in all hES cell lines tested. RNA was isolated from these as well as from cells harvested at the time of seeding to form EBs (day 0 ). The expression of genes indicative of differentiation to distinct embryonic lineages (ectoderm, mesoderm and endoderm) and to germ cells was then analyzed in each RNA sample by quantitative RT-PCR (Fig. 1).

During their growth in suspension as EBs the hES cells of each line underwent extensive differentiation, evidenced by the marked down regulation of OCT4 and up regulation of several genes typical of various cell lineages of three germ layers. Some genes showed similar temporal changes in expression pattern in all the hES lines. For example, OCT4 expression values were similar at each time point for all the hES lines suggesting that each committed to differentiate according to a similar timetable (Fig. 1I). Transcription factors that were consistently upregulated during EB differentiation across all hES cell lines included the proendocrine marker NeuroD1 (Fig. 1D), the early pancreatic endoderm marker IPF1 (Fig. 1J), the solute carrier family 2 (SLC2A2) (Fig. 1D), and Glucokinase (Fig. 1G). However, there were substantial differences between the cell lines in the levels of gene expression. For instance, the culture adapted $\mathrm{H} 14$ cells produced the lowest transcript levels of IPF1, SLC2A2 and Glucokinase, but
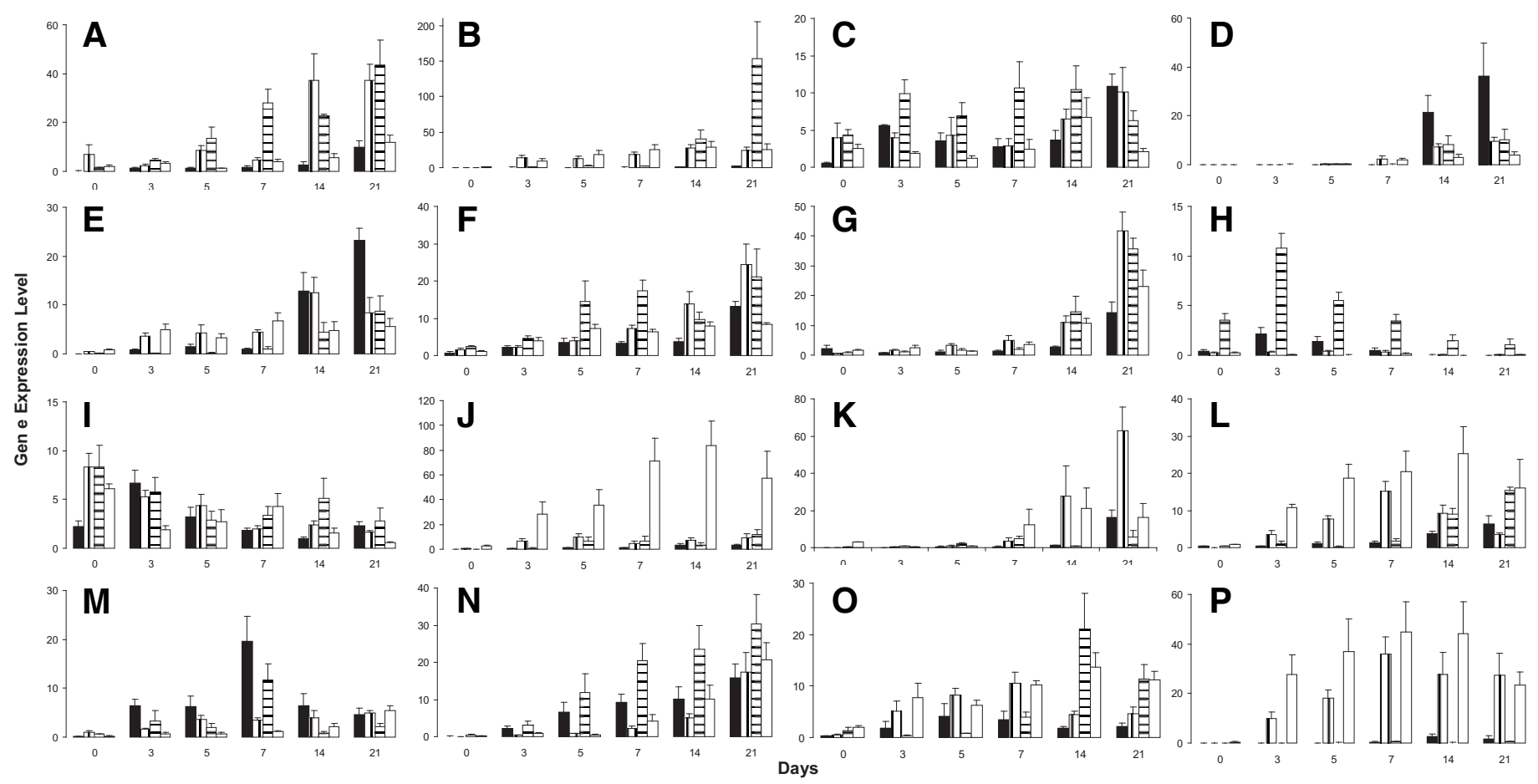

Fig. 1. Mean+SEM normalised gene expression values for (A) DEAD/H BOX 4 (VASA), (B) Solute Carrier Family 2 (SLC2A2), (C) Synaptonemal Complex Protein 3 (SCP3), (D) Neurogenic Differentiation 1 (Neuro D1), (E) ISL 1 Transcription Factor (ISL 1), (F) Growth/Differentiation Factor 9 (GDF9), (G) Glucokinase (GCK), (H) Deleted in AZoospermia-Like (DAZL), (I) Octamer-binding Transcription Factor 4 (OCT4), (J) Insulin Promoter Factor 1 (IPF1), (K) Insulin (INS), (L) Cadherin 5 (CDH5), (M) Myogenic Differentiation Antigen 1 (MYOD1), (N) Microtubule-Associated Protein 2 (MAP2), (O)

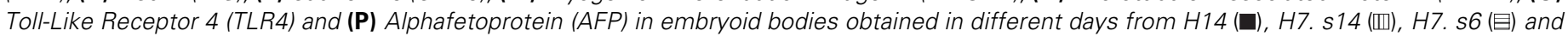
Shef3 ( $\square)$ hES cell lines. 

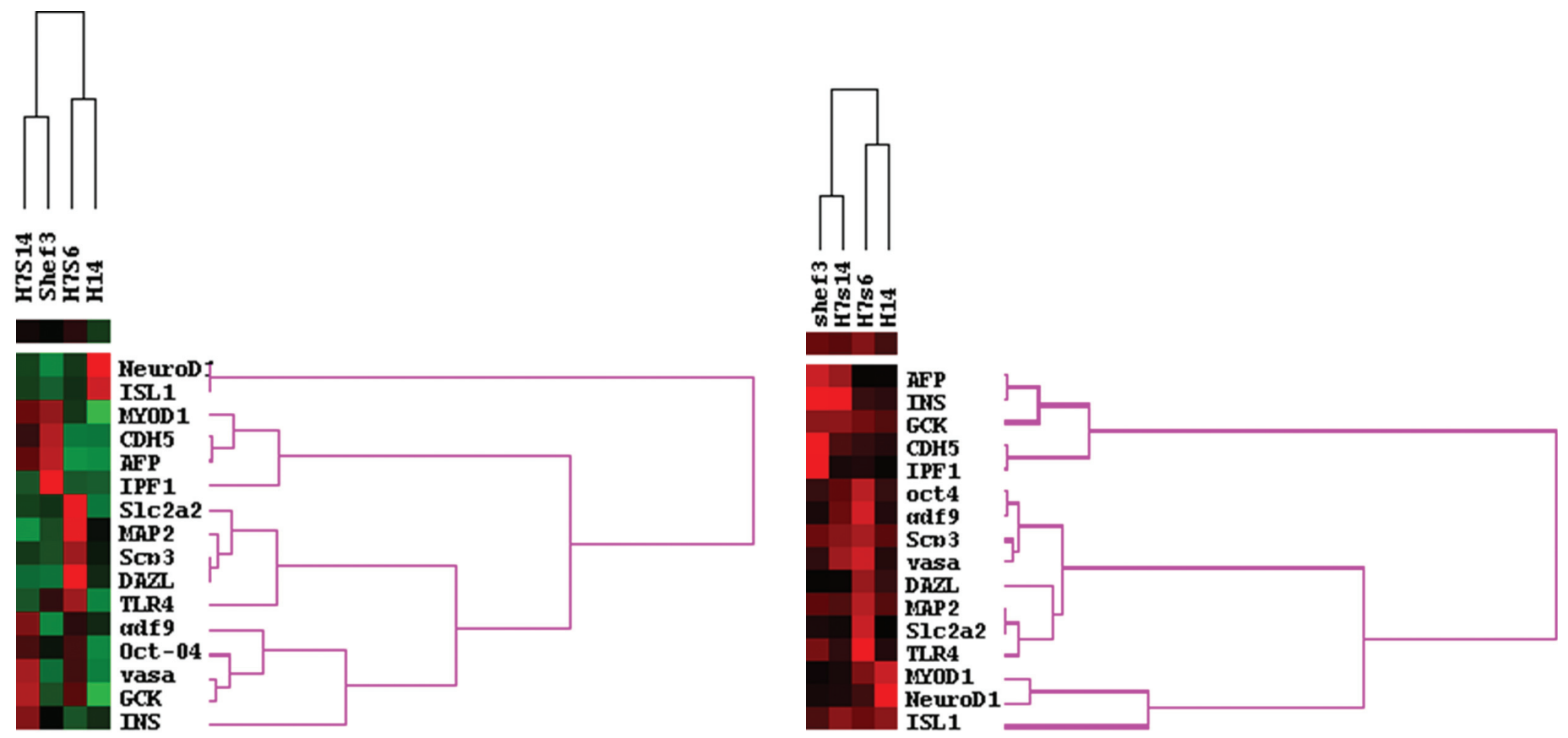

Fig. 2 (left). Cluster analysis of gene expression patterns of differentiated karyotypically normal (H7.s14 and Shef3) and abnormal (H7.s6 and H14) human ES cells. Red indicates a higher distance from average pattern of gene expression, black denotes similar pattern of gene expression compared to average pattern of expression and green denotes low activity. The karyotypically normal hES lines (H7.s 14 and Shef3) clustered together while the karyotypically abnormal hES lines (H7.s6 and H14) also clustered together but separately from the normal lines.

Fig. 3 (right). Cluster analysis of consistency in gene expression patterns between different batches of particular hES lines. Within a $h E S$ line the pattern of gene expression was variable for various genes between different batches. When the consistency in gene expression patterns for a particular gene between different batches of a particular $h E S$ line was investigated, those $h E S$ lines that were karyotypically normal showed a similar pattern of consistency and clustered together. Red indicates a higher variation and relatively lower consistency in gene expression between different batches of a specific hES line and black denotes less variation and relatively higher consistency in gene expression between different batches of a particular stem cell line.

the expression levels of these genes was higher in and did not differ significantly between the EBs of diploid and culture adapted H7 sublines.

On the other hand, several other genes that were up-regulated upon differentiation were expressed quite differently between karyotypically normal and abnormal lines. For example, AFP expression was up-regulated in both the karyotypically diploid lines (H7.s14 and Shef3) from day 3 onwards, but there was hardly any expression of this gene in either of the culture adapted sublines (H7.s6 and H14) before day 21 of EB culture (Fig. 1P). Another example was MYOD1, an embryonic mesoderm and myogenic marker, though in this case the normal lines differed somewhat (Fig. 1M): the EBs from the diploid lines, Shef3 and H7.s14 showed a steady increase of MYOD1 expression with expression peaking at day 21 of EB differentiation in both lines, whereas in both the karyotypically abnormal lines, MYOD1 expression increased from day 3 to 7 but decreased thereafter. The expression of Islet-1 (Fig. 1E), CDH5 (Fig. 1L) and TLR4 (Fig. 1O) followed the same pattern whereby these transcription factors were up-regulated during the early to mid EB differentiation (day 0-7 for Islet-1 and day 3-7 for CDH5 and TLR4) in the H7.s14 and Shef3 EBs, whereas they were induced to a lower level and appeared later in the EBs of the culture adapted cells. Moreover, the expression of Insulin was indeed significantly higher in day 14 and day $21 \mathrm{H} 7 . \mathrm{s} 14$ and Shef3 EBs (Fig. 1K). Taken together, the cellular changes associated with culture adaptation appear to have impeded endothelial (CDH5 and TLR4) and pancreatic lineage (Islet-1 and Insulin) selection in $\mathrm{H} 7$ cells.

Several genes were preferentially up-regulated in the EBs of the karyotypically abnormal hES cells. Thus, $\mathrm{H} 14$ and H7.s6 showed a marked increase of MAP2 expression from days 0 - 7 compared to the diploid normal lines, suggesting that culture adaptation may predispose differentiating cells in early EBs toward a neuronal lineage. The expression of DAZL, a marker for gametogenesis in humans, was also particularly marked during EB differentiation in $\mathrm{H} 14$ and $\mathrm{H} 7 . \mathrm{s} 6$ cells, but was undetectable in H7.s14 and Shef3 (Fig. 1H).

Using principal component analysis (PCA), we calculated an average pattern of gene expression for all four hES lines. Next, we scored each hES line for the distance of its expression pattern for each gene from the calculated average gene expression pattern for all four lines. Using these scores and cluster analysis we grouped both the hES lines with similar patterns of gene expression, and the genes with similar expression patterns between the lines (Fig. 2). In this analysis, the karyotypically normal hES lines (H7.s14 and Shef3) clustered together whereas the karyotypically abnormal hES lines (H7.s6 and $\mathrm{H} 14)$ also clustered together but separately from the normal lines.

Using the standard deviation of the PCA scores as indicator of consistency in gene expression values between different batches 
of hES cells within one line, those hES lines that were karyotypically normal showed also a similar pattern of consistency in gene expression between different batches and clustered together (Fig. 3). For example, there is a high variation of DAZL expression in replicates of EBs from $\mathrm{H} 7 . \mathrm{s} 6$ and $\mathrm{H} 14$ (red box), which otherwise was not observed in H7.s14 and Shef3 cells (black box). Thus, culture adaptation may instigate a chaotic differentiation paradigm and lineage selection during hES cell differentiation. Thus, culture adaption does appear to influence the patterns of spontaneous differentiation that occur in EBs.

\section{Discussion}

There is accumulating evidence that human ES cell lines differ in their propensity to differentiate into distinct cell types (Osafune et al. 2008; Pal et al. 2009). This may be due, in part, to inherent differences relating either to the origins of the lines from different cells within the embryo, or from embryos at subtly different stages of development, or to the different genotypes of the embryos from which they were derived. Alternatively, differences may be due to the acquisition of mutations and epigenetic changes during long term culture. For example, it has been reported that some karyotypically abnormal hES cells differentiate less in xenograft teratomas than their normal counterparts (Herszfeld et al. 2006). In that study it was found that teratomas obtained from the abnormal cells contained a much greater proportion of primitive, undifferentiated cells, compared to teratomas from diploid hES cells. However, it was not clear whether there was a difference in the type of differentiated tissues formed in teratomas from normal and abnormal cells. Our results show not only that different hES cell lines exhibit differences in their developmental potential during in vitro differentiation, but also that their propensity for committing to different lineages of differentiation may change upon prolonged culture.

Of the hES cell lines that we studied, H7.s14 and $\mathrm{H} 7 . \mathrm{s} 6$ are sublines of the same original line: they did not cluster together in their pattern of differentiation, indicating that the observed different patterns of differentiation are likely the consequences of changes that have occurred during culture (Fig. 2). The other early passage diploid hES line, Shef3, is not only unrelated genetically to the early passage diploid $\mathrm{H} 7 . \mathrm{s} 14$ line but is male, whereas $\mathrm{H} 7$ is female: they were also derived in two different laboratories under different conditions. Nevertheless the EBs derived from these diploid lines showed similar, though not identical, patterns of differentiation compared to the two other culture adapted lines (Fig. 2). Thus, differences in differentiation pattern correlated better with culture adaptation, than with variation in inherent genotype or derivation'techniques. We observed the same trend of clustering when we examined the consistency in gene expression during differentiation (Fig. 3).

It seems likely that culture adaptation arises as a consequence of random genetic or epigenetic changes providing a growth advantage to the variant cells (Baker et al. 2007; Draper et al. 2004; Maitra et al. 2005; Olariu et al. 2010). Such advantage might arise because a mutation increases the probability that a stem cell will undergo self-renewal rather than commit to differentiation when it divides, or because it confers some survival advantage, perhaps by reducing propensity for apoptosis. Since the commonly observed karyotypic changes associated with culture adaptation of hES, cells typically involve whole chromosomes or large chromosomal segments, most genes that are amplified and over-expressed may not be directly involved in the process of adaptation, but merely 'hitch-hike' with whichever gene provides the selective advantage. Thus, distinct patterns of differentiation as a result of adaptation could be mere accidental consequences of altered gene expression patterns associated with, but not necessarily causal associated with, adaptation.

Alternatively, in some cases, there might be a direct causal link between altered differentiation and adaptation. Cultures of hES cells are typically heterogeneous with mixtures of the undifferentiated stem cells and their differentiated derivatives. In such a situation it is likely that signaling between different cell types might affect the overall population dynamics of the culture as a whole. For example, it has been suggested that fibroblasts differentiating from hES cells form a 'niche' that promotes proliferation of undifferentiated cells by production of insulin-like growth factor (IGF) (Bendall et al. 2007). Another example is a suggestion that endodermal cells derived from differentiating hES cells produce factors such as bone morphogenetic protein-2 (BMP-2) that induce differentiation of remaining undifferentiated cells in the culture (Pera et al. 2004). In such a situation, maintenance of the undifferentiated stem cells would depend on other factors, perhaps produced by other differentiated derivatives, inhibiting the action of BMP, for example. Accordingly, taking this as an example, a selective advantage might be gained by cells that do not spontaneously generate endodermal cell types, or that generate more of a cell type producing the putative inhibitor factor. It is striking that reduced endoderm differentiation, indicated by reduced expression of AFP, is a feature of both the adapted cells we have analyzed in this study.

Culture adaptation of hES cells on prolonged passage presents both problems and opportunities for their eventual exploitation. Certainly for the use of hES cell derivatives in regenerative medicine, it will be crucial to minimize the acquisition of genetic and epigenetic changes that interfere with cell function, or promote oncogenicity. On the other hand, elucidating how specific mutations influence the behaviour of the undifferentiated cells could provide insights into how these cells can be deliberately manipulated for specific purposes. Our present results suggest that culture adaptation may provide one tool for learning how to manipulate the lineages chosen by hES cells when they are induced to differentiate.

\section{Materials and Methods}

\section{Cell culture}

Human ES cell lines $\mathrm{H} 7$ and $\mathrm{H} 14$ (Thomson et al. 1998) were obtained from Dr James Thomson, University of Wisconsin. Shef3 was produced by a microdrop technique using cryopreserved human embryos by the Center for Stem Cell Biology, Sheffield under the license from Human Fertilization and Embryology Authority (Aflatoonian et al. 2010). The karyotypes of all cell lines were analyzed by standard Giemsa-banding techniques. $\mathrm{H} 7 . \mathrm{s} 6$ is a culture adapted late passage subline of $\mathrm{H} 7$ that had acquired chromosomal changes by passage 60 and had a $46, X X, \operatorname{der}(6) t(6 ; 17)(q 27 ; q 1)$ karyotype, whereas H7.s14 is an early passage, karyotypically diploid $(46, \mathrm{XX})$ subline (Draper et al. 2004; Enver et al. 2005; Maitra et al. 2005). The subline of H14 used in the study had become trisomic for the whole chromosome 17, but had no other karyotypic changes $(47, X Y)(2)$. Shef3 was diploid and karyotypically normal 
$(46, X Y)$.

Undifferentiated cultures of hES cells were maintained in KnockOut DMEM (Invitrogen, CA, USA) supplemented with $20 \%$ KnockOut Serum Replacement (Invitrogen) and $4 \mathrm{ng} / \mathrm{ml}$ basic fibroblast growth factor (bFGF) (Invitrogen) under a humidified atmosphere of $5 \% \mathrm{CO}_{2}$ in air at $37^{\circ} \mathrm{C}$ (Amit et al. 2000). For sub-cultivation, the cells were harvested by scraping following treatment with $2 \mathrm{ml}$ of $1 \mathrm{mg} / \mathrm{ml}$ collagenase type IV (Invitrogen) in DMEM:F12 (Invitrogen) per T25 flask for 5 to 7 minutes at $37^{\circ} \mathrm{C}$, dispersed by scraping with $3 \mathrm{~mm}$ glass beads (Phillip-Harris Scientific), centrifuged at $68 \times \mathrm{g}$ for 3 minutes and then seeded onto fresh MEF feeder layers that had been washed once with PBS immediately prior to use.

\section{Induction of differentiation in hES cells}

To induce differentiation, approximately $1 \times 10^{7}$ undifferentiated hES cells from one T25 flask were disaggregated using $1 \mathrm{mg} / \mathrm{ml}$ collagenase IV (GIBCO-BRL) for five minutes. Detached colonies were disintegrated into homogenous size of clusters (between five to ten cells) using $3 \mathrm{~mm}$ sterile glass beads and centrifuged at $68 \mathrm{x} g$ for 3 minutes. Cell clumps were transferred to $100-\mathrm{mm}$ non-adherent bacterial-grade Petri dishes (BibbySterilin, Staffs, UK) in medium as described above. The suspension culture resulted in spontaneous differentiation characterized by initial formation of small aggregates which developed into embryoid bodies (EBs). We examined spontaneous differentiation in EBs without controlling the cell cluster size to favor unbiased differentiation and to minimize selection in different hES cell lines. The culture medium was changed every other day to eliminate cell debris and for long-term cultivation. For each cell line, five replicate EB cultures were prepared: EBs were collected from each replicate culture at day-3, 5, 7, 14 and 21 for RNA extraction.

\section{RNA extraction, cDNA synthesis and quantitative PCR}

Total RNA was isolated from undifferentiated human ES cells and from EBs at various stages of differentiation. TRI reagent (Sigma, Poole, UK) was added to the harvested cells and total RNA was extracted using TRI reagent standard protocol supplied by the manufacturer. Extracted RNA was treated with DNasel (DNA-free Kit; Ambion, Huntingdon, UK) to remove genomic DNA contamination from samples. First-strand cDNA synthesis was performed using Oligo-dT primers and the Superscript II reverse transcriptase system (Invitrogen).

Quantitative PCR reactions of hES cells and EBs cDNA were performed using the Assay-on-Demand technology (Applied Biosystems, CA, USA). Each reaction consisted of 10 microliter of Jump-Start TaqReadyMix (Sigma), 1 microliter of 1:10 diluted cDNA, 1 microliter of Assay-on-Demand technology and 8 microliter nuclease-free water (Sigma). PCR amplifications were initiated at $95^{\circ} \mathrm{C}$ for $10 \mathrm{~min}$ followed by $35-50$ cycles of $95^{\circ} \mathrm{C}$ for 15 seconds and $60^{\circ} \mathrm{C}$ for 60 seconds. PCR reactions were performed using an iCycleriQ (Bio-Rad Laboratories Ltd., Hemel Hempstead, UK). PCR reactions for each sample were done in triplicates.

The Quantitative PCR data were analyzed using the comparative CT method (Livak \& Schmittgen 2001). Briefly, the difference in cycle times, $\Delta \mathrm{CT}$, was determined as the difference between the tested gene and the reference housekeeping gene, ACTIN. We then obtained $\Delta \Delta C T$ by finding the difference between groups. The fold change (FC) was calculated as $\mathrm{FC}=2^{-\Delta \Delta C}$

\section{Statistical Analysis}

The relative expression levels of 16 genes, were normalized based on ACTIN expression. Data were collected from six different time points and five different batches/passages of each of the four hES lines. In some of the batches the low quantity or quality of RNA obtained did not allow correct measurement of particular gene expressions in that batch. Hence, if majority of data in an experimental batch of a particular $\mathrm{hES}$ cell line was missing, that batch was not included in the analysis. In addition if in a batch due to technical problems one or two data points were missing then the mean value from the other batches of that particular $\mathrm{hES}$ line at the same time point was used to estimate the missing data points. This was a rare event.

A Principal Component Analysis (PCA) based approach was used to establish a quantitative indicator to the patterns of different gene expressions between different batches of different hES line. To allow a behavioral (non-absolute) comparison, all data patterns were normalized to a 0 to 1 scale across all genes. The standard deviation (SD) of the PCA scores on the first factor of all their constituent batches acted as an inherent quality indicator. SD values were defined as weighted averages, relative to the importance of eigenvalues, of the PCA scores for each pattern. Average linkage clustering was used to analyze the consistency in pattern of gene expression between different batches of a particular hES line.

qPCR data were normalized separately per gene to examine the consistency of gene expression for three replicate samples collected at the same time point. Only relative activities were used for across gene behavior comparisons. Cluster analysis was used to define most closely related hES lines.

\section{Acknowledgements}

Authors wish to thank Mrs. L. Ruban, Miss K. Amps and Mr. B. Aflatoonian for their assistance. This work was supported by grants from the MRC and by ESTOOLS, an Integrated Project funded by the European Commission under the Sixth Framework Program.

\section{References}

AFLATOONIAN B., RUBAN L., SHAMSUDDIN S., BAKER D., ANDREWS P. \& MOORE H. (2010) Generation of Sheffield (Shef) human embryonic stem cell lines using a microdrop culture system. In vitro Cell. Dev. Biol. 46: 236-241.

AMIT M., CARPENTER M.K., INOKUMA M.S., CHIU C.P., HARRIS C.P., WAKNITZ M.A., ITSKOVITZ-ELDOR J. \& THOMSON J.A. (2000) Clonally derived human embryonic stem cell lines maintain pluripotency and proliferative potential for prolonged periods of culture. Dev. Biol. 227: 271-278.

ANDREWS P.W. (2002) From teratocarcinomas to embryonic stem cells. Philos Trans. Royal Soc. London 357: 405-417.

ANDREWS P.W., MATIN M.M., BAHRAMI A.R., DAMJANOV I., GOKHALE P. \& DRAPER J.S. (2005) Embryonic stem (ES) cells and embryonal carcinoma (EC) cells: opposite sides of the same coin. Biochem Soc Trans 33: 1526-1530.

ATKIN N.B. \& BAKER M.C. (1982) Specific chromosome change, i(12p), in testicular tumours? Lancet 2: 1349.

BAKER D.E., HARRISON N.J., MALTBY E., SMITH K., MOORE H.D., SHAW P.J. HEATH P.R., HOLDEN H. \& ANDREWS P.W. (2007) Adaptation to culture of human embryonic stem cells and oncogenesis in vivo. Nat Biotechno/25: 207215.

BENDALLS.C., STEWART M.H., MENENDEZP., GEORGE D., VIJAYARAGAVAN K., WERBOWETSKI-OGILVIE T., RAMOS-MEJIA V., ROULEAU A., YANG J. BOSSE M., LAJOIE G. \& BHATIA M. (2007) IGF and FGF cooperatively establish the regulatory stem cell niche of pluripotent human cells in vitro. Nature 448: 1015-1021.

DRAPER J.S., SMITH K., GOKHALE P., MOORE H.D., MALTBY E., JOHNSON J., MEISNER L., ZWAKA T.P., THOMSON J.A. \& ANDREWS P.W. (2004) Recurrent gain of chromosomes $17 q$ and 12 in cultured human embryonic stem cells. Nat Biotechno/22: 53-54.

ENVERT., SONEJIS., JOSHIC., BROWN J., IBORRA F., ORNTOFT T., THYKJAER T., MALTBY E., SMITH K., DAWUD R.A., JONES M., MATIN M., GOKHALE P., DRAPER J. \& ANDREWS P.W. (2005) Cellular differentiation hierarchies in normal and culture-adapted human embryonic stem cells. Hum Mol Genet 14: 3129-3140.

HERSZFELD D., WOLVETANG E., LANGTON-BUNKER E., CHUNG T.L., FILIPCZYK A.A., HOUSSAMI S., JAMSHIDI P., KOH K., LASLETT A.L., MICHALSKA A., NGUYEN L., REUBINOFF B.E., TELLIS I., AUERBACH J.M., ORDING C.J., LOOIJENGA L.H. \& PERA M.F. (2006) CD30 is a survival factor 
and a biomarker for transformed human pluripotent stem cells. Nat Biotechnol 24: 351-357.

LIVAK K.J. \& SCHMITTGEN T.D. (2001) Analysis of relative gene expression data using real-time quantitative PCR and the 2(-Delta Delta C(T)) Method. Methods San Diego, Calif 25: 402-408.

MAITRA A., ARKING D.E., et al. (2005) Genomic alterations in cultured human embryonic stem cells. Nat Genet 37: 1099-1103.

OLARIU V., HARRISON N.J., COCA D., GOKHALE P.J., BAKER D., BILLINGS S., KADIRKAMANATHAN V. \& ANDREWS P.W. (2010) Modeling the evolution of culture-adapted human embryonic stem cells. Stem Cell Res. 4: 50-56.

OSAFUNE K., CARON L., BOROWIAK M., MARTINEZ R.J., FITZ-GERALD C.S., SATO Y., COWAN C.A., CHIEN K.R. \& MELTON D.A. (2008) Marked differences in differentiation propensity among human embryonic stem cell lines. Nat Biotechno/26: 313-315.
PAL R., TOTEY S., MAMIDI M.K., BHAT V.S. \& TOTEY S. (2009) Propensity of human embryonic stem cell lines during early stage of lineage specification controls their terminal differentiation into mature cell types. Exp. Biol. Med. 234 1230-1243.

PERA M.F., ANDRADE J., HOUSSAMI S., REUBINOFF B., TROUNSON A. STANLEY E.G., WARD-VAN OOSTWAARD D. \& MUMMERY C. (2004) Regulation of human embryonic stem cell differentiation by BMP-2 and its antagonist noggin. J Cel/ Sci117: 1269-1280.

SKOTHEIM R.I., MONNI O., MOUSSES S., FOSSA S.D., KALLIONIEMI O.P. LOTHE R.A. \& KALLIONIEMI A. (2002) New insights into testicular germ cell tumorigenesis from gene expression profiling. Cancer Res 62: 2359-2364.

THOMSON J.A., ITSKOVITZ-ELDOR J., SHAPIRO S.S., WAKNITZ M.A., SWIERGIEL J.J., MARSHALL V.S. \& JONES J.M. (1998) Embryonic stem cell lines derived from human blastocysts. Science 282: 1145-1147.

\section{Further Related Reading, published previously in the Int. J. Dev. Biol.}

Novel roles for Notch, Wnt and Hedgehog in hematopoesis derived from human pluripotent stem cells

Chantal Cerdan and Mickie Bhatia

Int. J. Dev. Biol. (2010) 54: 955-964

Comparative study of mouse and human feeder cells for human embryonic stem cells Livia Eiselleova, Iveta Peterkova, Jakub Neradil, Iva Slaninova, Ales Hamp and Petr Dvorak Int. J. Dev. Biol. (2008) 52: 353-363

Spa-1 regulates the maintenance and differentiation of human embryonic stem cells Young-Jin Lee, Hee-Young Nah, Seok-Ho Hong, Ji-Won Lee, Ilkyung Jeon, Jhang Ho Pak, Joo-Ryung Huh, Sung-Hoon Kim, Hee-Dong Chae, Byung-Moon Kang, Chul Geun Kim and Chung-Hoon Kim Int. J. Dev. Biol. (2008) 52: 43-53

Neural differentiation from human embryonic stem cells in a defined adherent culture condition Hossein Baharvand, Narges-Zare Mehrjardi, Maryam Hatami, Sahar Kiani, Mahendra Rao and Mahdi-Montazer Haghighi Int. J. Dev. Biol. (2007) 51: 371-378

Differentiation of human embryonic stem cells into hepatocytes in 2D and 3D culture systems in vitro Hossein Baharvand, Seyed M. Hashemi, Saeid Kazemi Ashtiani and Ali Farrokhi Int. J. Dev. Biol. (2006) 50: 645-652

5 yr ISI Impact Factor $(2009)=3.253$

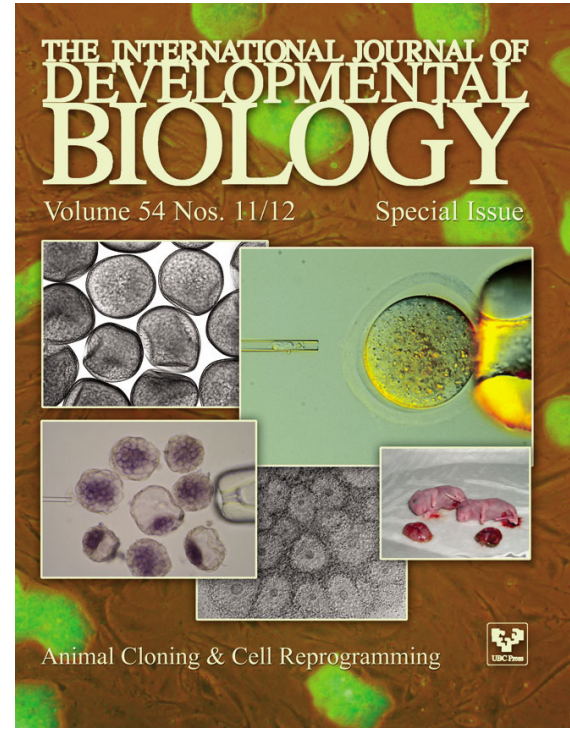

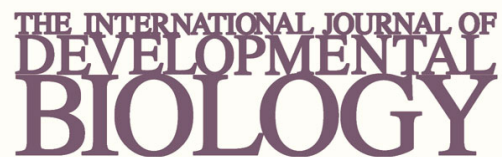

Volume 54 Nos. $6 / 7$
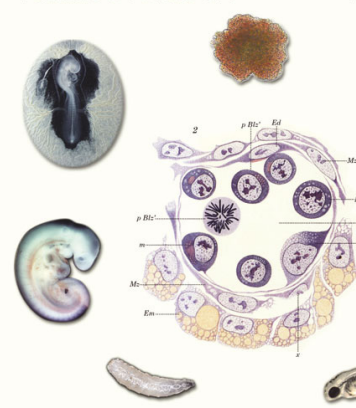

Developmental Hematopoiesis
Special Issue
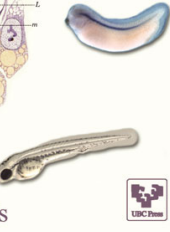

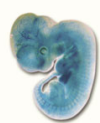

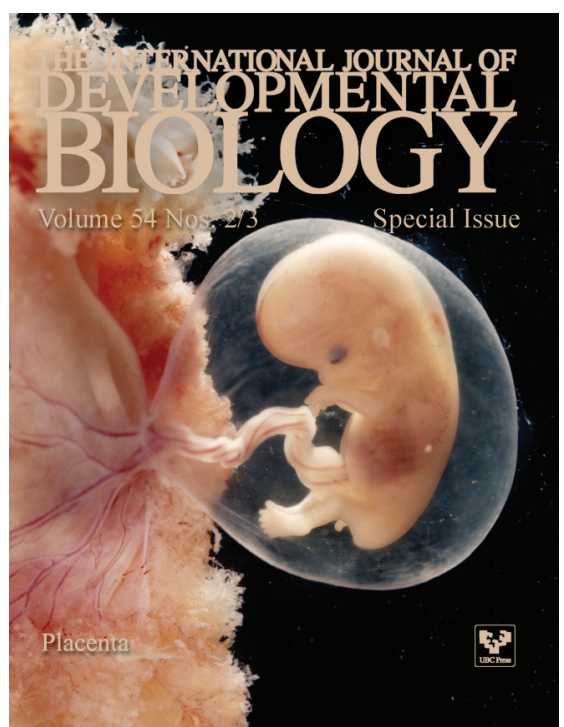

